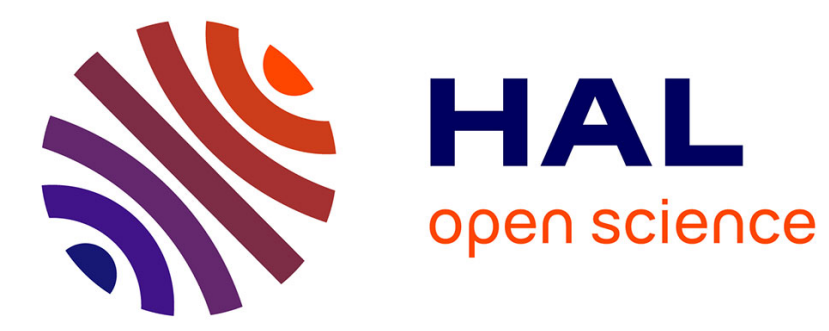

\title{
Reactive $\mathrm{ZnO} / \mathrm{Ti} / \mathrm{ZnO}$ interfaces studied by hard x-ray photoelectron spectroscopy
}

Ronny Knut, Rebecka Lindblad, Sergey Grachev, Jean-Yvon Faou, Mihaela Gorgoi, Hakan Rensmo, Elin Sondergard, Olof Karis

\section{- To cite this version:}

Ronny Knut, Rebecka Lindblad, Sergey Grachev, Jean-Yvon Faou, Mihaela Gorgoi, et al.. Reactive $\mathrm{ZnO} / \mathrm{Ti} / \mathrm{ZnO}$ interfaces studied by hard x-ray photoelectron spectroscopy. Journal of Applied Physics, 2014, 115, pp.043714. 10.1063/1.4854636 . hal-00938244

HAL Id: hal-00938244

https://hal.science/hal-00938244

Submitted on 29 Jan 2014

HAL is a multi-disciplinary open access archive for the deposit and dissemination of scientific research documents, whether they are published or not. The documents may come from teaching and research institutions in France or abroad, or from public or private research centers.
L'archive ouverte pluridisciplinaire HAL, est destinée au dépôt et à la diffusion de documents scientifiques de niveau recherche, publiés ou non, émanant des établissements d'enseignement et de recherche français ou étrangers, des laboratoires publics ou privés. 


\title{
Reactive $\mathrm{ZnO} / \mathrm{Ti} / \mathrm{ZnO}$ interfaces studied by hard $\mathrm{x}$-ray photoelectron spectroscopy
}

\author{
Ronny Knut, ${ }^{1, a)}$ Rebecka Lindblad, ${ }^{1}$ Sergey Grachev, ${ }^{3}$ Jean-Yvon Faou, ${ }^{3}$ Mihaela Gorgoi, ${ }^{2}$ \\ Håkan Rensmo, ${ }^{1}$ Elin Søndergård, ${ }^{3}$ and Olof Karis ${ }^{1}$ \\ ${ }^{1}$ Department of Physics and Astronomy, Uppsala University, Box 516, 75120 Uppsala, Sweden \\ ${ }^{2}$ Helmholtz-Zentrum Berlin für Materialien und Energie, Albert-Einstein-Str. 15, D-12489 Berlin, Germany \\ ${ }^{3}$ Unité Mixte CNRS/Sain-Gobain Recherche, 39 Quai Lucien Lefranc, 93303 Aubervilliers, France
}

(Received 8 September 2013; accepted 9 December 2013; published online 28 January 2014)

The chemistry and intermixing at buried interfaces in sputter deposited $\mathrm{ZnO} / \mathrm{Ti} / \mathrm{ZnO}$ thin layers were studied by hard x-ray photoelectron spectroscopy. The long mean free path of the photoelectrons allowed for detailed studies of the oxidation state, band bending effects, and intrinsic doping of the buried interfaces. Oxidation of the Ti layer was observed when $\mathrm{ZnO}$ was deposited on top. When $\mathrm{Ti}$ is deposited onto $\mathrm{ZnO}, \mathrm{Zn}$ Auger peaks acquire a metallic character indicating a strong reduction of $\mathrm{ZnO}$ at the interface. Annealing of the stack at $200{ }^{\circ} \mathrm{C}$ results in further reduction of $\mathrm{ZnO}$ and oxidation of Ti. Above $300^{\circ} \mathrm{C}$, oxygen transport from the bulk of the $\mathrm{ZnO}$ layer takes place, leading to re-oxidation of $\mathrm{ZnO}$ at the interface and further oxidation of Ti layer. Heating above $500^{\circ} \mathrm{C}$ leads to an intermixing of the layers and the formation of a $\mathrm{Zn}_{x} \mathrm{TiO}_{y}$ compound. (C) 2014 AIP Publishing LLC. [http://dx.doi.org/10.1063/1.4854636]

\section{INTRODUCTION}

Reactive interfaces are essential for many thin film applications. In general, it is hard to investigate the state and structure of such systems since the characterization methods themselves can alter the interface. $\mathrm{ZnO} / \mathrm{Ti}$ thin films are a typical example of a stack containing a highly reactive interface. $\mathrm{Ti}$ is an electropositive element and it has a tendency to reduce $\mathrm{ZnO}$ due to its lower enthalpy of oxide formation. Despite their complexity, $\mathrm{ZnO} / \mathrm{Ti}$ based thin films find use in several areas. Ti forms an ohmic contact to $\mathrm{ZnO}$, ${ }^{1}$ which is indispensable for a wide range of applications exploiting the semiconducting properties of $\mathrm{ZnO} .^{2}$ This interface can also be found in the glazing industry where a $\mathrm{ZnO} / \mathrm{Ti} / \mathrm{Ag}$ coating is used as a low emissivity infrared filter. In this case, an ultrathin Ti layer serves as an adhesion enhancer between the oxide and the noble metal. ${ }^{3}$ In both cases, the origin of the peculiar electronic behavior and of the bonding reinforcement is under discussion. ${ }^{4-6}$ The reduction of $\mathrm{ZnO}$ by Ti results in the creation of $\mathrm{O}$ vacancies in the $\mathrm{ZnO}$, giving rise to reduced interfacial resistivity and n-doping. ${ }^{4}$ The $\mathrm{ZnO} / \mathrm{Ti}$ interface is very sensitive to annealing. Above a certain temperature, which scatters between 300 and $600^{\circ} \mathrm{C}$, a $\mathrm{ZnTiO}_{x}$ compound forms at the interface. The studies published so far have been performed on rather thick $(>25 \mathrm{~nm})$ Ti layers allowing for techniques such as diffraction, ${ }^{6}$ which does not provide direct information on the interface itself. Other observations were based on destructive sample preparation in order to access the interface properties ${ }^{5}$ and the conclusions of this study were limited by the reactivity of Ti.

$\mathrm{X}$-ray photoelectron spectroscopy (XPS) is a powerful nondestructive method able to retrieve not only chemical composition of a material but also the oxidation state of atoms. The laboratory XPS set-ups are usually surface

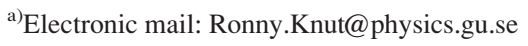

sensitive as they use soft $\mathrm{x}$-rays of $1.2-1.5 \mathrm{keV}$ energy, limiting the probing depth to a few nanometers. Lately, the use of hard x-rays in modern synchrotron radiation facilities combined with new photoelectron detection technology extend the use of XPS as the probing depth can be varied between 1 and $20 \mathrm{~nm}^{7}$ Hard $\mathrm{x}$-ray photoelectron spectroscopy (HAXPES) opens up the field for investigations of multilayer films and buried interfaces. Recently, the technique has been successfully applied to study the intermixing of metallic multilayers as well as chemical states at interfaces. ${ }^{8-10}$ The present report is a detailed HAXPES study of sputterdeposited $\mathrm{ZnO} / \mathrm{Ti}$ and $\mathrm{Ti} / \mathrm{ZnO}$ interfaces, giving new insight on the behavior of this kind of systems. We were able to quantify the extent of $\mathrm{ZnO}$ reduction in as-deposited $\mathrm{ZnO} / \mathrm{Ti}$ stacks and found a strong dependence on the sequence of deposition, which further impacted the chemical state and stoichiometry of the interface during annealing.

\section{EXPERIMENTAL}

The samples were deposited in a vacuum sputterdeposition chamber with the base pressure of $4 \times 10^{-5} \mathrm{~Pa}$. $\mathrm{Si}$ wafers with a native oxide were used as substrates. The chamber is equipped with three magnetrons allowing for deposition of a complete stack. For all the layers, dcsputtering was used with Ar as a working gas. In order to obtain $\mathrm{ZnO}$ films, a $\mathrm{Zn}$ target was used in combination with flow of $\mathrm{O}_{2}$ admixed to Ar. The oxygen flow was adjusted for the best stoichiometry of the $\mathrm{ZnO}$ films. The deposition rates were $1.7 \mathrm{~nm} / \mathrm{s}$ for $\mathrm{ZnO}$ and $0.13 \mathrm{~nm} / \mathrm{s}$ for Ti films. Three sample structures were grown, $\mathrm{ZnO}(50 \mathrm{~nm}) / \mathrm{Ti}(4 \mathrm{~nm}) /$ $\mathrm{ZnO}(5 \mathrm{~nm}) / \mathrm{Mo}(7 \mathrm{~nm}), \mathrm{ZnO}(50 \mathrm{~nm}) / \mathrm{Ti}(4 \mathrm{~nm}) / \mathrm{Mo}(7 \mathrm{~nm})$, and $\mathrm{ZnO}(50 \mathrm{~nm}) / \mathrm{Ti}(5 \mathrm{~nm})$. In the first two samples, Mo served as a capping layer to protect the Ti from oxidation in air. These two samples will be denoted $\mathrm{ZnO} / \mathrm{Ti} / \mathrm{ZnO}$ and $\mathrm{ZnO} / \mathrm{Ti}$, respectively, with the sample geometry illustrated in Fig. 1. 


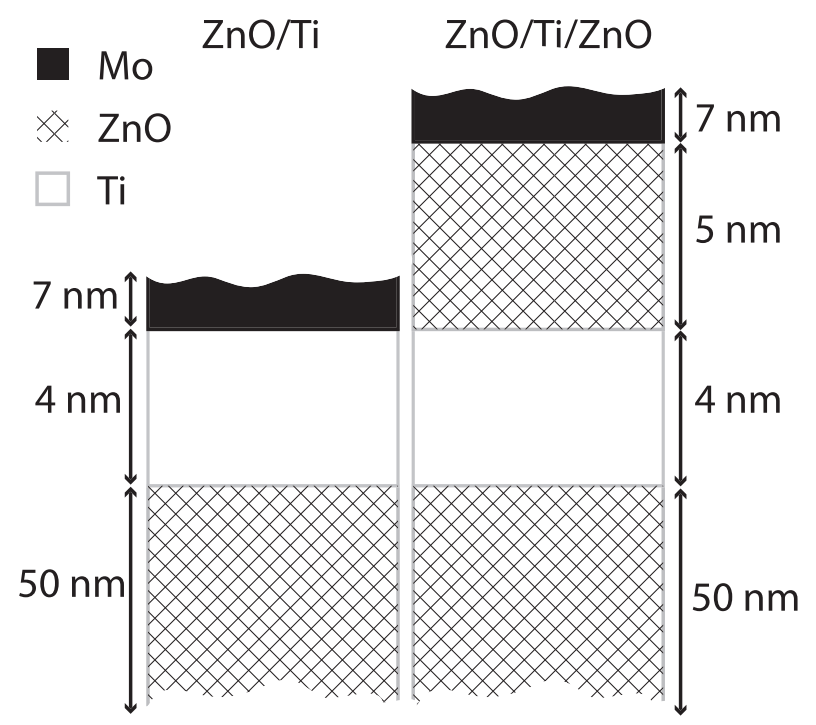

FIG. 1. The nominal sample geometry of the samples $\mathrm{ZnO} / \mathrm{Ti}$ and $\mathrm{ZnO} / \mathrm{Ti} / \mathrm{ZnO}$. Both samples are capped with Mo (filled black) and grown on $50 \mathrm{~nm} \mathrm{ZnO}$ (striped black). A $4 \mathrm{~nm}$ Ti layer (white) is deposited on the $\mathrm{ZnO}$ and an additional $5 \mathrm{~nm} \mathrm{ZnO}$ layer is grown on the Ti layer for sample $\mathrm{ZnO} / \mathrm{Ti} / \mathrm{ZnO}$.

The HAXPES experiments were conducted at the KMC1 beamline, using the HIKE end-station, at Bessy II at Helmholtz Zentrum Berlin. This beamline offers photon energies ranging between 2 and $12 \mathrm{keV}$ with high resolution. ${ }^{7}$ In all the presented data, a photon energy of $4 \mathrm{keV}$ was used unless stated otherwise. This energy provides a good compromise between peak intensity, resolution, and depth sensitivity $(\sim 5 \mathrm{~nm}$ inelastic mean free path). The analysis chamber is equipped with an $\mathrm{Ar}^{+}$sputter gun which was used for sputtering the Mo cap to decrease its thickness and increase the photoelectron yield from deeper layers. The sample manipulator is equipped with a heating stage which can heat samples up to $\sim 800^{\circ} \mathrm{C}$. The samples were heated at a rate of $20^{\circ} \mathrm{C} / \mathrm{min}$ until the required temperature, between $200^{\circ} \mathrm{C}$ and $550^{\circ} \mathrm{C}$, was reached and kept there for $10 \mathrm{~min}$. After each annealing step, the sample was cooled down to room temperature (RT) before the core level spectra were recorded. All spectra were energy calibrated relative to an $\mathrm{Au}$ reference which was in electrical contact with the samples, hence zero binding energy (BE) corresponded to the Fermi level. Pure sputter-deposited materials ( $\mathrm{Zn}, \mathrm{ZnO}$, $\mathrm{TiO}_{2}$ ) were also examined and used as reference samples. The change of the binding energy of a particular core level denotes the chemical shift and it depends on the chemical environment. ${ }^{8,11}$ In particular, Ti $2 p$ peaks exhibit large chemical shifts, while $\mathrm{Zn} 2 \mathrm{p}$ peaks do not. ${ }^{12}$ Therefore, we have also measured the Zn LMM Auger which shows a distinctive difference between the metallic and oxidized states. However, the probing depth of Auger electrons is insensitive to the photon energy and restricted to a few $\mathrm{nm}$, so a reasonable signal could not be obtained for all sample geometries.

\section{RESULTS AND DISCUSSION}

Fig. 2(a) shows the Ti $2 p$ spectrum of a reference $\mathrm{TiO}_{2}$ sample obtained at $4 \mathrm{keV}$ photon energy. This spectrum
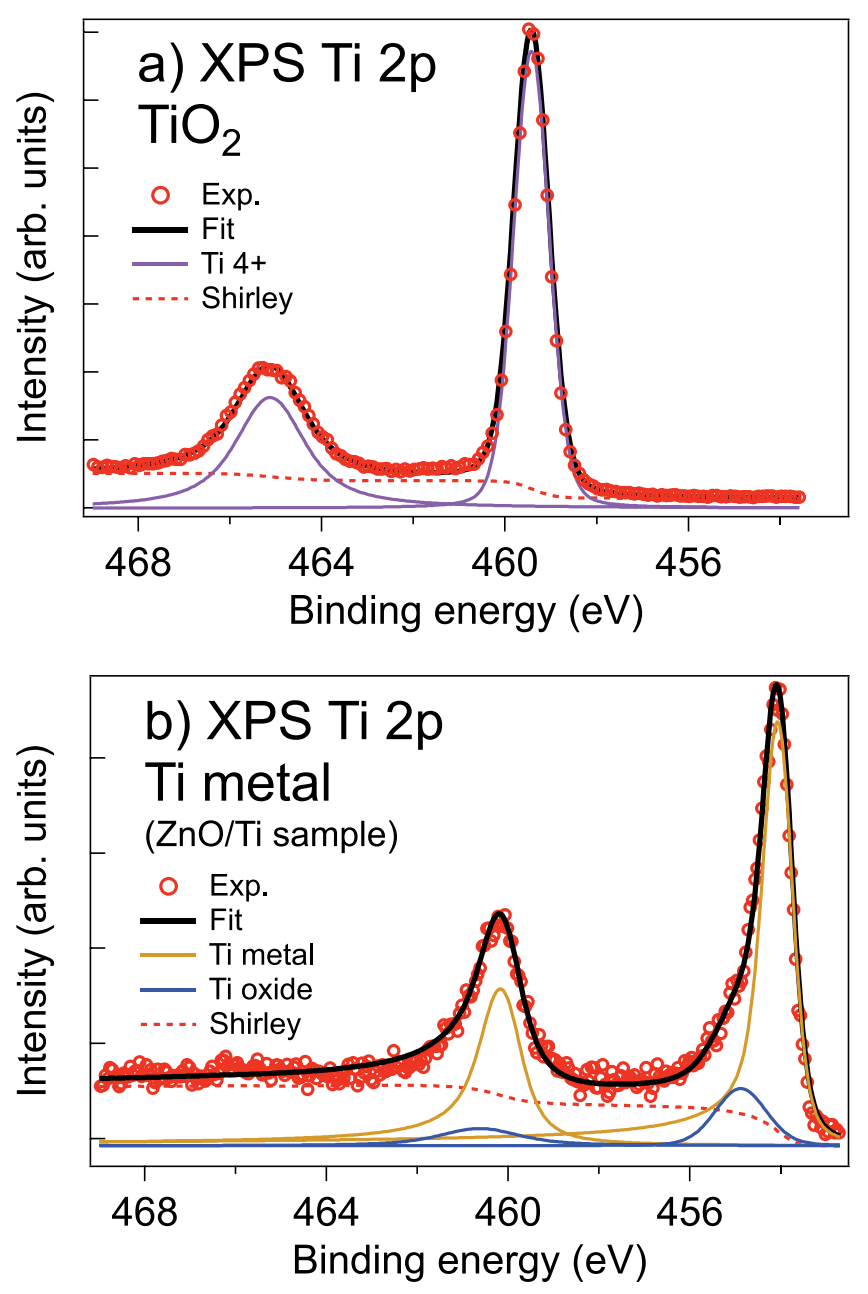

FIG. 2. (a) $\mathrm{Ti} 2 \mathrm{p}$ spectrum of $\mathrm{TiO}_{2}$ recorded with $4 \mathrm{keV}$ photon energy. A good fit is obtained using a single peak for each spin orbit split core level corresponding to $\mathrm{Ti}_{3 / 2,1 / 2}^{4+}$. (b) $\mathrm{Ti} 2 \mathrm{p}$ spectrum of $\mathrm{ZnO} / \mathrm{Ti}$ sample recorded with $4 \mathrm{keV}$ photon energy. The sample contains mainly metallic $\mathrm{Ti}^{\circ}$. A weak oxidation is found which is represented by the blue spectra.

corresponds to $\mathrm{Ti}^{4+}$ where the core level is spin-orbit split by $5.7 \mathrm{eV}$ (Ref. 12) into $\mathrm{Ti}_{3 / 2}^{4+}(459.4 \mathrm{eV} \mathrm{BE})$ and $\mathrm{Ti}_{1 / 2}^{4+}$. A good fit is obtained by a single peak at both spin orbit split levels with a Gaussian broadening of $0.83 \mathrm{eV}$ convoluted with a Lorenzian broadening of $0.22 \mathrm{eV}$ and $1.4 \mathrm{eV}$ for the $\mathrm{Ti}_{3 / 2}^{4+}$ and $\mathrm{Ti}_{1 / 2}^{4+}$ peaks, respectively. The Lorenzian broadening is a lifetime effect of the core hole. The $\mathrm{Ti}_{1 / 2}^{4+}$ core hole has an additional decay channel, the Coster-Kroenig transition, ${ }^{13}$ which shortens its lifetime and hence increases the Lorenzian broadening compared to the $\mathrm{Ti}_{3 / 2}^{4+}$ core hole. The Gaussian broadening of $0.83 \mathrm{eV}$ accounts for the experimental resolution $(0.35 \mathrm{eV}$ in the present experiments) but also suggest some degree of disorder in the film. A Shirley background (red dotted line in Fig. 2(a)) is included in all fittings of spectra. ${ }^{14}$ The Ti $2 p$ spectrum for the $\mathrm{ZnO} / \mathrm{Ti}$ sample, as deposited, is presented in Fig. 2(b). This spectrum shows a reasonably good fit by using a Doniach-Sunjic line profile (brown) which is appropriate for metallic systems. ${ }^{15}$ The spin orbit splitting for the metallic $\mathrm{Ti}$ is $6.12 \mathrm{eV}$, in accordance with literature. ${ }^{12}$ The Doniach-Sunjic profile is convoluted with a Gaussian broadening of $0.62 \mathrm{eV}$ and exhibits an asymmetry parameter of 0.1 and Lorenzian widths of 
$0.22 \mathrm{eV}$ and $0.65 \mathrm{eV}$ for the $\mathrm{Ti}_{3 / 2}^{0}(454.1 \mathrm{eV} \mathrm{BE})$ and $\mathrm{Ti}_{1 / 2}^{0}$ peaks, respectively. There is also a weak doublet represented by the blue peaks which corresponds to slightly oxidized Ti. This oxidation is due to the chemical reaction of $\mathrm{Ti}$ with $\mathrm{ZnO}$ at the interface.

Unlike the $\mathrm{ZnO} / \mathrm{Ti}$, the $\mathrm{ZnO} / \mathrm{Ti} / \mathrm{ZnO}$ sample shows a high extent of Ti oxidation before annealing, Fig. 3. This spectrum shows not only a large amount of $\mathrm{Ti}^{4+}$ but also a significant amount of lower oxidation states. The BE positions of $\mathrm{Ti}^{3+}$ and $\mathrm{Ti}^{2+}$ correspond well with literature values. ${ }^{12}$ The $\mathrm{BE}$ of the metallic peak is approximately $0.4 \mathrm{eV}$ higher than for the metallic peak in Fig. 2(b) indicating that the electronic structure of the thin layer of metallic Ti is affected by the interface to the oxide. ${ }^{8,11}$

Fig. 4(a) shows the Ti $2 p$ core levels after annealing at different temperatures for the $\mathrm{ZnO} / \mathrm{Ti}$ sample. The $\mathrm{RT}$ spectrum which was presented in Fig. 2(b) is also shown here for comparison. The dotted lines correspond to the BE of Ti oxidation states $(4+, 3+, 2+, 0)$ from high to low $\mathrm{BE}$, respectively. After annealing at $200^{\circ} \mathrm{C}$, we observe a large increase of $\mathrm{Ti}^{2+}$, indicating oxidation of $\mathrm{Ti}$ due to oxygen from $\mathrm{ZnO}$. The oxidation of $\mathrm{Ti}$ is further advanced at higher annealing temperature and after annealing at $550{ }^{\circ} \mathrm{C}$ the $\mathrm{Ti}$ layer is almost completely oxidized to $\mathrm{Ti}^{4+}$. We also show a spectrum obtained with $2 \mathrm{keV}$ photon energy after $550^{\circ} \mathrm{C}$ annealing (red dotted line). This spectrum shows a higher contribution from non- or low-oxidation components than the spectrum recorded at $4 \mathrm{keV}$. Since lower photon energies gives a decreased probing depth, this confirms that the Ti is oxidized from below and that the oxidation is not complete close to the Mo capping layer.

Fig. 4(b) shows the temperature dependent evolution of $\mathrm{Ti} 2 \mathrm{p}$ in the $\mathrm{ZnO} / \mathrm{Ti} / \mathrm{ZnO}$ sample, which was largely oxidized already after deposition. For comparison, the RT spectrum from Fig. 3 is also included in Fig. 4(b). The RT spectra were obtained with both $4 \mathrm{keV}$ and $2 \mathrm{keV}$ photon energy. The metallic and low oxidation states are less pronounced with the $2 \mathrm{keV}$ photon energy compared to the $4 \mathrm{keV}$ confirming that the Ti oxide is situated closer to the surface. The metallic component has mostly disappeared after annealing

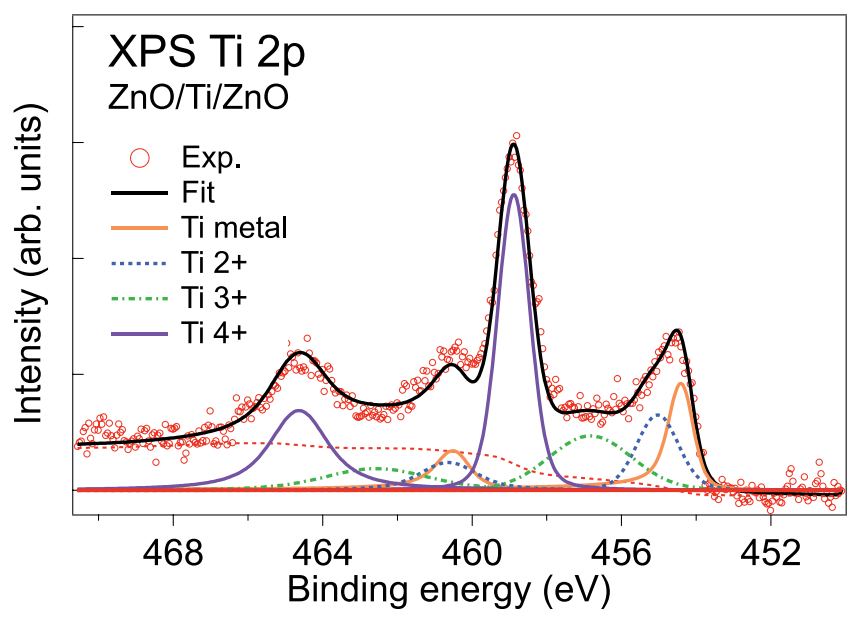

FIG. 3. Ti $2 \mathrm{p}$ spectrum of sample $\mathrm{ZnO} / \mathrm{Ti} / \mathrm{ZnO}$ recorded with $4 \mathrm{keV}$ photon energy. The sample is highly oxidized. A weak metallic contribution is still present but the main $\mathrm{Ti}$ contribution corresponds to $\mathrm{Ti}^{4+}$ as in $\mathrm{TiO}_{2}$.
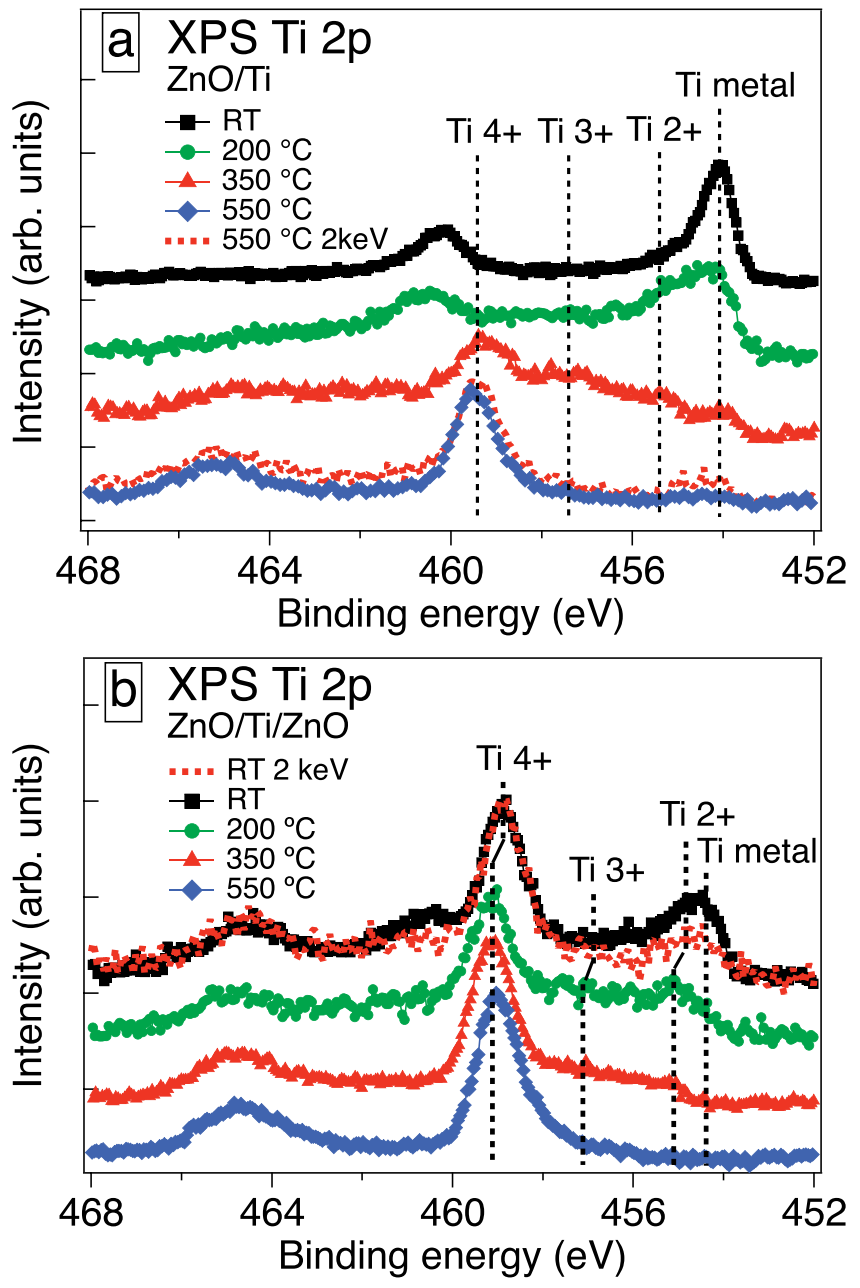

FIG. 4. Ti $2 p$ spectra after annealing. The vertical dotted lines mark the binding energy of $\mathrm{Ti}$ oxidation states $(4+, 3+, 2+, 0)$. (a) $\mathrm{ZnO} / \mathrm{Ti}$ sample. The strong metallic component is largely oxidized already after annealing at $200^{\circ} \mathrm{C}$. A weak metallic component is observed after $550^{\circ} \mathrm{C}$ using $2 \mathrm{keV}$, suggesting that the oxidation is not complete close to the Mo interface. (b) $\mathrm{ZnO} / \mathrm{Ti} / \mathrm{ZnO}$ sample. The initially weak metallic component is almost completely lost after annealing at $200^{\circ} \mathrm{C}$. The higher contribution of oxidized Ti when using $2 \mathrm{keV}$ photon energy at RT suggests an initial oxidation mainly from the top $\mathrm{ZnO}$ layer.

at $200^{\circ} \mathrm{C}$. The oxidation state is almost completely $\mathrm{Ti}^{4+}$ after annealing at $550^{\circ} \mathrm{C}$. The vertical black dotted lines correspond to rigid $\mathrm{BE}$ differences between the oxidized components and it is found that the $\mathrm{Ti}^{4+}$ component shifts after annealing. It is also found that the $\mathrm{Ti}^{4+}$ in the $\mathrm{ZnO} / \mathrm{Ti} / \mathrm{ZnO}$ sample has $0.3 \mathrm{eV}$ lower $\mathrm{BE}$ than in the $\mathrm{ZnO} / \mathrm{Ti}$ sample after annealing. This could be due to band bending effects since the Ti-oxides have close contact with the Mo metal in the $\mathrm{ZnO} / \mathrm{Ti}$ sample.

A quantitative estimation of the equivalent thickness of metallic $\mathrm{Ti}$, assuming layered structures, is presented in Fig. 5. The amount of the metallic component is derived by assuming a nominal Ti layer of $4 \mathrm{~nm}$ and comparing the area of Ti $2 p$ oxide and metallic peaks after a peak fit of the spectra in Figs. 4(a) and 4(b). The probing depth effect is accounted for by assuming that $\mathrm{TiO}_{x}$ is formed in the lower (closer to the substrate) part of the Ti layer. For the $\mathrm{ZnO} / \mathrm{Ti} / \mathrm{ZnO}$ sample, an additional oxidation from the top (closer to the surface) is accounted for. The error bars 


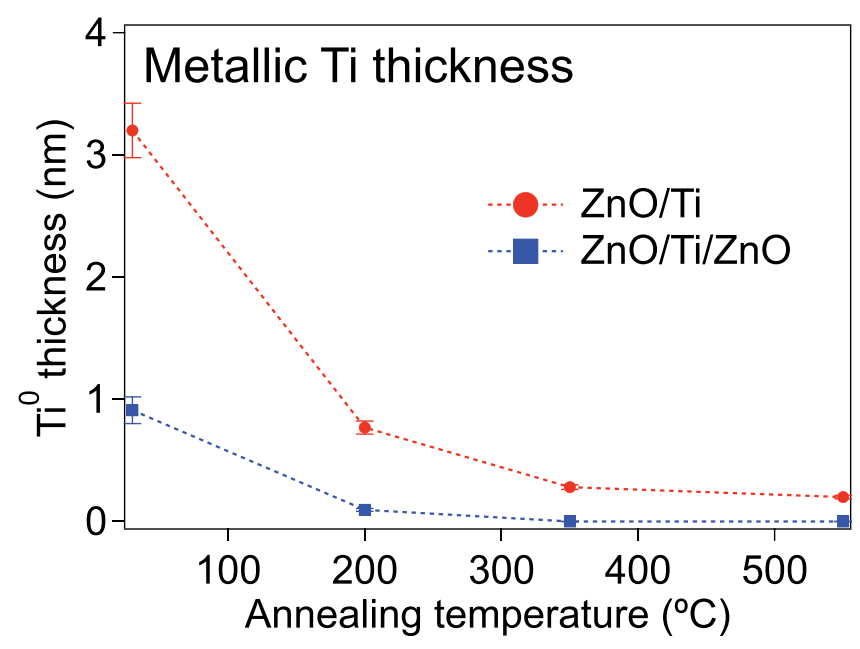

FIG. 5. Estimated thickness of metallic Ti after annealing, obtained from Figs. 4(a) and 4(b). The Ti is very sensitive to oxidation from the $\mathrm{ZnO}$ layer already after heat treatment at $200^{\circ} \mathrm{C}$.

correspond to an uncertainty in separating the metallic and the low oxidation state of Ti. According to Fig. 5, before annealing, $\mathrm{a} \sim 1 \mathrm{~nm}$ thick oxide layer is formed at the lower interface while at the top interface (only sample $\mathrm{ZnO} / \mathrm{Ti} / \mathrm{ZnO}$ ), a $\sim 2 \mathrm{~nm}$ oxidized Ti layer is formed, resulting in a $\sim 1 \mathrm{~nm}$ thick metallic Ti component for sample $\mathrm{ZnO} / \mathrm{Ti} / \mathrm{ZnO}$ and a $3 \mathrm{~nm}$ thick metallic component for sample $\mathrm{ZnO} / \mathrm{Ti}$ before annealing. After annealing at $200{ }^{\circ} \mathrm{C}$, the $\mathrm{Ti}$ in the $\mathrm{ZnO} / \mathrm{Ti} / \mathrm{ZnO}$ sample is almost fully oxidized. A metallic Ti layer of $\sim 1 \mathrm{~nm}$ still remains in the $\mathrm{ZnO} / \mathrm{Ti}$ sample, in which the oxidized $\mathrm{Ti}$ is mostly in a low oxidation state.

The $\mathrm{O} 1 \mathrm{~s}$ and $\mathrm{Zn} 2 \mathrm{p}_{3 / 2}$ core level peaks for the $\mathrm{ZnO} / \mathrm{Ti}$ sample are shown in Figs. 6(a) and 6(b), respectively. Background intensities, obtained from survey spectra (not shown), are used for normalization such that the intensities of different core level intensities can be compared without considering variations in the synchrotron ring current, i.e., photon intensities. These backgrounds are relatively unaffected by annealing which also ensures that core level intensities can be compared between different annealing temperatures. The $\mathrm{O}$ 1s at RT shows a distinct double peak feature where the peak at high BE $(\sim 532 \mathrm{eV})$ likely comes from oxygen on the Mo surface, while the peak around $530 \mathrm{eV} \mathrm{BE}$ is due to oxygen in the $\mathrm{ZnO}$ layer. The vertical black dotted lines in both Figs. 6(a) and 6(b) correspond to the $\mathrm{BE}$ position of $\mathrm{O} 1 \mathrm{~s}$ and $\mathrm{Zn} 2 \mathrm{p}_{3 / 2}$, respectively for n-doped $\mathrm{ZnO}$ and they are also close to the BE positions of metallic $\mathrm{Zn} 2 \mathrm{p}_{3 / 2}$ and $\mathrm{O} 1 \mathrm{~s}$ usually found in $\mathrm{TiO}_{2} \cdot{ }^{12,16-18}$ Both the $\mathrm{Zn} 2 \mathrm{p}_{3 / 2}$ and $\mathrm{O}$ 1s exhibit broadened peaks at RT which is probably a consequence of two effects. The reduction of $\mathrm{ZnO}$, due to the Ti layer, will likely create a gradient of intrinsic doping close to the interface which will be manifested as line broadening. Also, the broadening can be induced by the band bending often found in metal/semiconductor interfaces leading to a Schottky barrier at the interface. Although $\mathrm{ZnO} / \mathrm{Ti}$ usually form an ohmic contact, this does not ensure that band bending is absent. ${ }^{19}$

The area of the $\mathrm{O} 1 \mathrm{~s}$ peak increases as the sample is annealed, indicating a diffusion of oxygen towards the
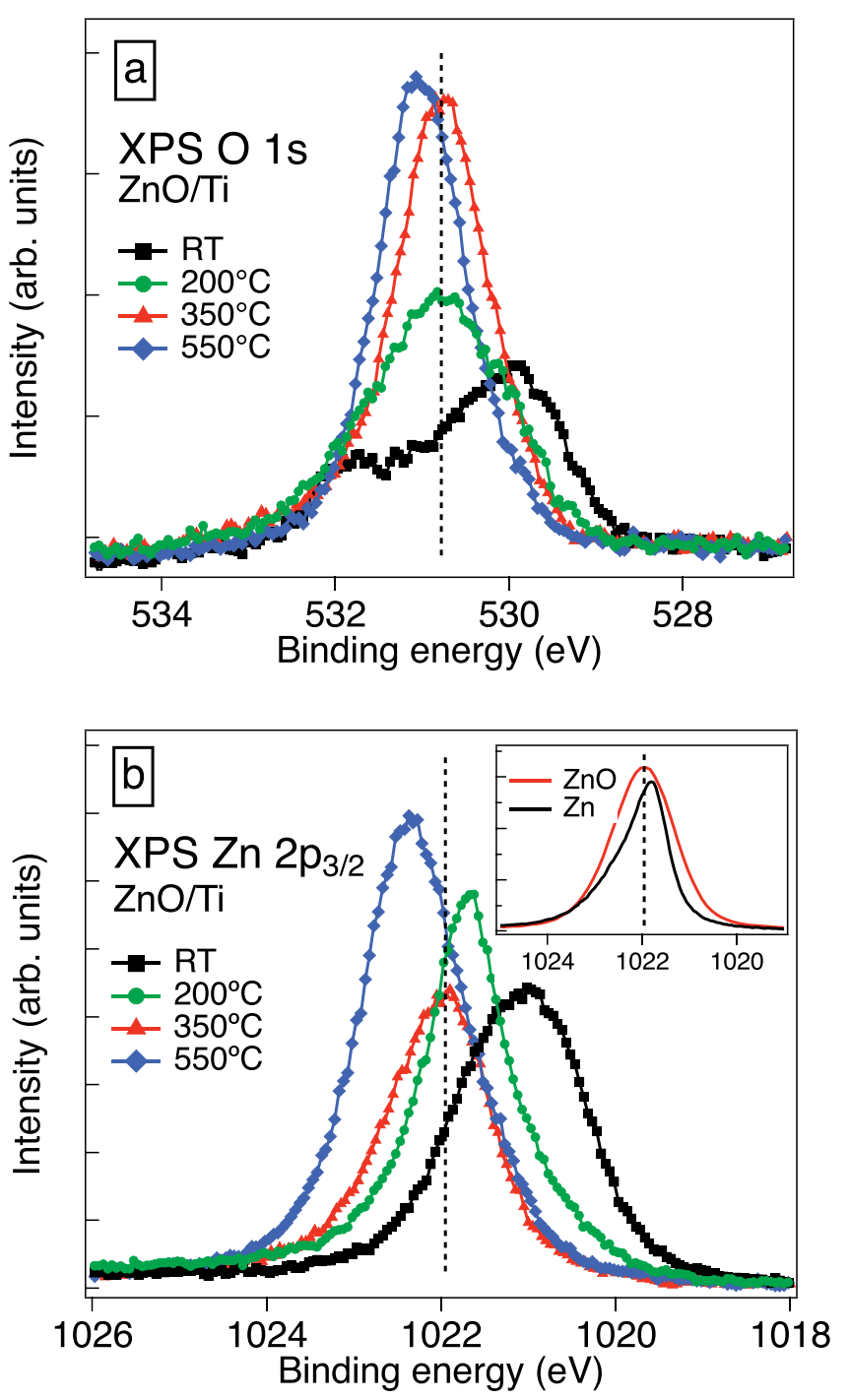

FIG. 6. (a) XPS of $\mathrm{O} 1 \mathrm{~s}$ in the $\mathrm{ZnO} / \mathrm{Ti}$ sample. A large intensity increase is observed after annealing to $350^{\circ} \mathrm{C}$ which is consistent with oxygen diffusion towards the surface. (b) XPS of $\mathrm{Zn} 2 \mathrm{p}_{3 / 2}$ shows similar shifts as the $\mathrm{O} 1 \mathrm{~s}$ indicating changes in the Fermi level. After annealing to $200{ }^{\circ} \mathrm{C}$, an enhanced metallic component is observed. The insert shows the peak shapes for $\mathrm{Zn} 2 \mathrm{p}_{3 / 2}$ in $\mathrm{ZnO}$ and metallic $\mathrm{Zn}$.

sample surface. Both $\mathrm{O} 1 \mathrm{~s}$ and $\mathrm{Zn} 2 \mathrm{p}_{3 / 2}$ show similar $\mathrm{BE}$ shifts as the sample is annealed, which indicates changes in the Fermi level of $\mathrm{ZnO}$ due to increased intrinsic n-doping, likely due to the formation of oxygen vacancies. However, the $\mathrm{BE}$ and peak shape of $\mathrm{Zn} 2 \mathrm{p}_{3 / 2}$ after annealing at $200{ }^{\circ} \mathrm{C}$ have a strong resemblance to metallic $\mathrm{Zn}$ (referred to as the $\mathrm{Zn}^{0}$ component from here on), compare to inset in Fig. 6(b) which shows the $\mathrm{Zn} 2 \mathrm{p}_{3 / 2}$ for reference $\mathrm{ZnO}$ and metallic $\mathrm{Zn}$ samples. This change in oxidation state of $\mathrm{Zn}$ also explains the difference in BE shift between $\mathrm{Zn} 2 \mathrm{p}_{3 / 2}$ and $\mathrm{O} 1 \mathrm{~s}$ at this annealing temperature. Further evidence of the presence of the $\mathrm{Zn}^{0}$ component will be given below where we study the $\mathrm{Zn}$ Auger LMM spectra. After annealing at $350^{\circ} \mathrm{C}$, we observe an increase of the $\mathrm{O} 1 \mathrm{~s}$ area which corresponds to the strong oxidation of Ti. At this temperature, oxygen from the $\mathrm{ZnO}$ bulk begins to diffuse towards the surface, which also results in oxidation of the $\mathrm{Zn}^{0}$ component found after annealing at $200{ }^{\circ} \mathrm{C}$. The $\mathrm{Zn} 2 \mathrm{p}_{3 / 2}$ area shows a strong 
increase after annealing at $550{ }^{\circ} \mathrm{C}$ which indicates that the $\mathrm{ZnO}$ and $\mathrm{Ti} / \mathrm{TiO}_{2}$ are intermixing. The $\mathrm{BE}$ have become higher than found for highly n-doped $\mathrm{ZnO}$ (black dotted line) which indicates that a new compound has formed.

Comparing the area ratios between different atomic components, as a function of annealing temperature, provides additional information about the diffusion. In Figs. 7 (a) and 7(b), we have plotted the ratio between Ti $2 \mathrm{p}_{3 / 2}$ and $\mathrm{Zn} 2 \mathrm{p}_{3 / 2}$ areas and the $\mathrm{Zn} 2 \mathrm{p}_{3 / 2}$ and $\mathrm{O} 1 \mathrm{~s}$ areas, respectively. The differences in cross section were taken in consideration and the surface component was subtracted from the $\mathrm{O} 1 \mathrm{~s}$ peak. The error bars in both Figs. 7(a) and 7(b) are due to the uncertainty in normalizing the core-level intensities to the same photon exposure. Also, an additional error source is included for sample $\mathrm{ZnO} / \mathrm{Ti}$ in Fig. 7(b) due to the uncertainty of separating the bulk and surface component of oxygen. The $\mathrm{Ti} / \mathrm{Zn}$ ratios have been normalized to the value obtained before annealing (Fig. 7(a)). The $\mathrm{ZnO} / \mathrm{Ti}$ sample (red circles) show a dip of the $\mathrm{Ti} / \mathrm{Zn}$ ratio at $200{ }^{\circ} \mathrm{C}$ which could be related to the formation of $\mathrm{Zn}^{0}$ at $200^{\circ} \mathrm{C}$. However,
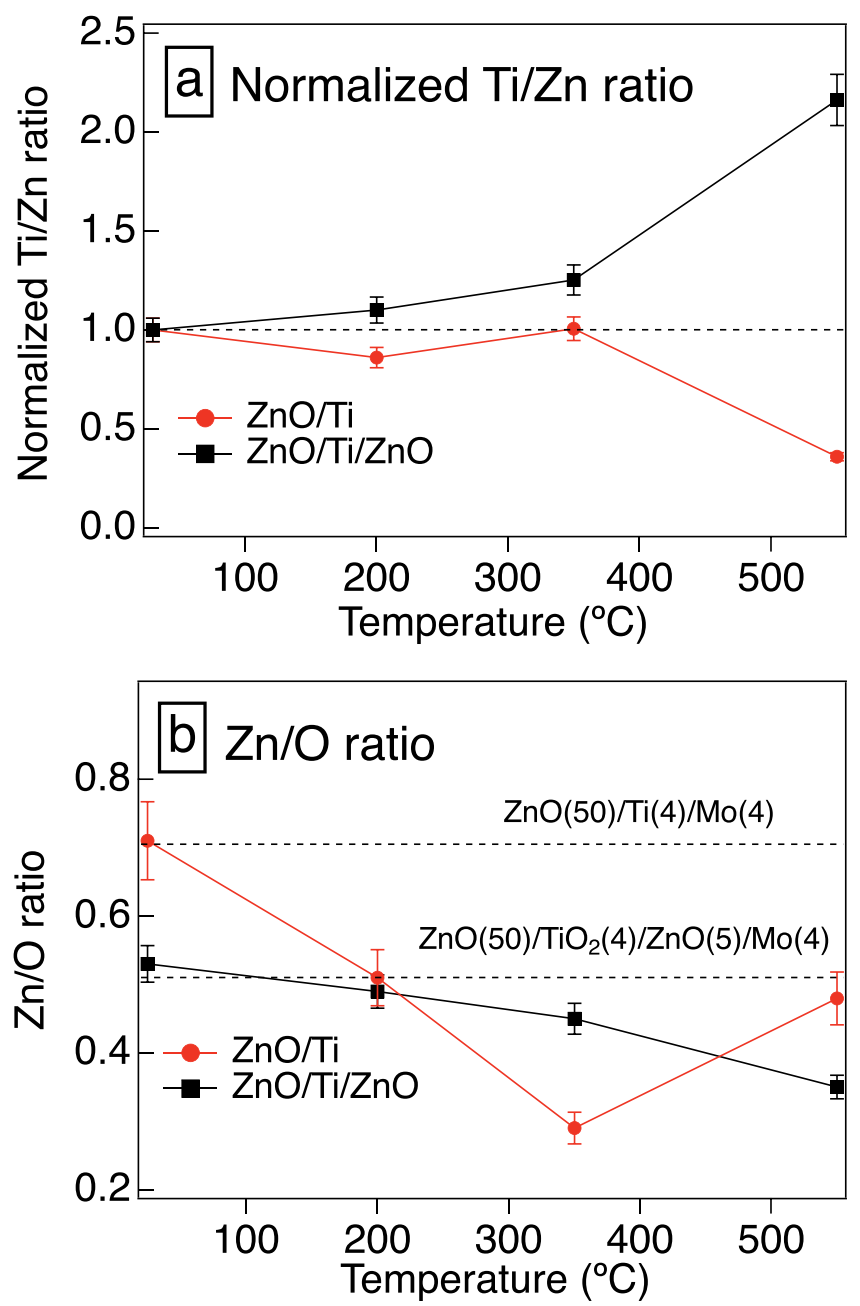

FIG. 7. (a) The ratio between $\mathrm{Ti} 2 \mathrm{p}_{3 / 2}$ and $\mathrm{Zn} 2 \mathrm{p}_{3 / 2}$ for both $\mathrm{ZnO} / \mathrm{Ti}$ (red circles) and $\mathrm{ZnO} / \mathrm{Ti} / \mathrm{ZnO}$ (black squares) samples. Both samples are normalized at the ratio obtained at RT. (b) The ratio between $\mathrm{Zn} 2 \mathrm{p}_{3 / 2}$ and $\mathrm{O} 1$ s for both $\mathrm{ZnO} / \mathrm{Ti}$ (red circles) and $\mathrm{ZnO} / \mathrm{Ti} / \mathrm{ZnO}$ (black squares) samples. The top and bottom horizontal black dotted lines corresponds to calculated $\mathrm{Zn} / \mathrm{O}$ ratios of stoichiometric $\mathrm{ZnO}$ in $\mathrm{ZnO} / \mathrm{Ti} / \mathrm{Mo}$ and $\mathrm{ZnO} / \mathrm{TiO}_{2} / \mathrm{ZnO} / \mathrm{Mo}$, respectively. the ratio regains its initial value at $350{ }^{\circ} \mathrm{C}$, which indicates that the $\mathrm{Zn}$ and $\mathrm{Ti}$ do not intermix at this temperature and that the main interlayer diffusion is due to oxygen. The $\mathrm{ZnO} / \mathrm{Ti} / \mathrm{ZnO}$ sample shows a generally increasing $\mathrm{Ti} / \mathrm{Zn}$ ratio with annealing temperature, which indicates that $\mathrm{Ti}$ is mixing with the top $\mathrm{ZnO}$ layer even for low annealing temperatures. At $550{ }^{\circ} \mathrm{C}$, the $\mathrm{Ti} / \mathrm{Zn}$ ratio strongly deviates from $\sim 1$ which suggests a strong intermixing between $\mathrm{ZnO}$ and $\mathrm{Ti}$ for both samples.

We have calculated the $\mathrm{Zn} / \mathrm{O}$ ratio corresponding to the two sample geometries, $\mathrm{ZnO}(50 \mathrm{~nm}) / \mathrm{Ti}(4 \mathrm{~nm}) / \mathrm{Mo}(4 \mathrm{~nm})$ and $\mathrm{ZnO}(50 \mathrm{~nm}) / \mathrm{TiO}_{2}(4 \mathrm{~nm}) / \mathrm{ZnO}(5 \mathrm{~nm}) / \mathrm{Mo}(4 \mathrm{~nm})$. The values are plotted in Fig. 7(b) as two horizontal black dotted lines at the top and bottom, respectively. The inelastic mean free paths for photoelectrons corresponding to O1s and $\mathrm{Zn} 2 \mathrm{p}$ were calculated with the QUASES software. ${ }^{20}$ From the photoemission spectra of Mo 3d (not shown), we estimate that a $4 \mathrm{~nm}$ thick Mo film remained after the initial $\mathrm{Ar}^{+}$sputtering of the stacks. The $\mathrm{Zn} / \mathrm{O}$ ratio for the as deposited $\mathrm{ZnO} / \mathrm{Ti}$ sample corresponds well to the calculated value of stoichiometric $\mathrm{ZnO}$, in accordance with a weak oxidation of the $\mathrm{Ti}$ layer. The oxygen diffusion into Ti decreases the ratio as the sample is annealed at $350{ }^{\circ} \mathrm{C}$. As suggested above, $\mathrm{ZnO}$ and $\mathrm{Ti}$ form a new compound at $550^{\circ} \mathrm{C}$, where the $\mathrm{Zn} / \mathrm{O}$ ratio approaches a ratio of $1: 2$. The valency of Ti evolves towards $4+$ suggesting the formation of a $\mathrm{Zn}_{2} \mathrm{TiO}_{4}$ spinel. ${ }^{21} \mathrm{X}$-ray diffraction studies (not shown) indicate the formation of new nanocrystalline phases but the peaks are too broad to conclusively confirm a spinel structure.

The $\mathrm{ZnO} / \mathrm{Ti} / \mathrm{ZnO}$ sample showed highly oxidized $\mathrm{Ti}$, Fig. 4(b), which corresponds well with the lower black dotted line in Fig. 7 (b) that indicates the calculated $\mathrm{Zn} / \mathrm{O}$ ratio of $\mathrm{ZnO}(50 \mathrm{~nm}) / \mathrm{TiO}_{2}(4 \mathrm{~nm}) / \mathrm{ZnO}(5 \mathrm{~nm}) / \mathrm{Mo}(4 \mathrm{~nm})$. The $\mathrm{Zn}$ $2 \mathrm{p}_{3 / 2}$ and $\mathrm{O} 1 \mathrm{~s}$ (not shown) have $\mathrm{BE}$ corresponding to n-doped $\mathrm{ZnO}$ (that is, corresponding to the vertical black dotted lines in Figs. 6(a) and 6(b)) and do not exhibit any BE shifts, nor significant line broadening, as the sample is heated. Since the main contribution to the core level intensities comes from the top $\mathrm{ZnO}$ layer, the upper part appears inert upon annealing. The $\mathrm{Zn} 2 \mathrm{p}_{3 / 2}$ intensity remains constant up to $350{ }^{\circ} \mathrm{C}$ while the $\mathrm{O} 1 \mathrm{~s}$ continuously increases which results in the decrease of the $\mathrm{Zn} / \mathrm{O}$ ratio (black squares in Fig. 7(b)). This suggests that the initial oxidation is a consequence of the top $\mathrm{ZnO}$ layer deposition while the oxidation during annealing is due to the oxygen diffusion from the bottom $\mathrm{ZnO}$ layer.

We were not able to record the Zn LMM Auger spectra from samples protected with a Mo cap due to the limited probing depth of Auger electrons. Instead, the $\mathrm{Zn} \mathrm{LMM}$ Auger spectra were measured on a $\mathrm{ZnO}(50 \mathrm{~nm}) / \mathrm{Ti}(5 \mathrm{~nm})$ sample without a capping layer as presented in Fig. 8. Even though the Ti layer has been directly exposed to ambient air, HAXPES indicates a significant amount of metallic Ti below the oxidized surface layer. The two peaks in the Auger spectra, marked by dotted lines, both appear in a reference spectrum of metallic $\mathrm{Zn}$ (not shown) while only the peak at lower kinetic energy is pronounced in the $\mathrm{Zn} \mathrm{LMM} \mathrm{spectra} \mathrm{of}$ $\mathrm{ZnO}$. The intensity ratio of these two peaks after annealing is plotted in the inset of Fig. 8 (red dotted line). The horizontal 


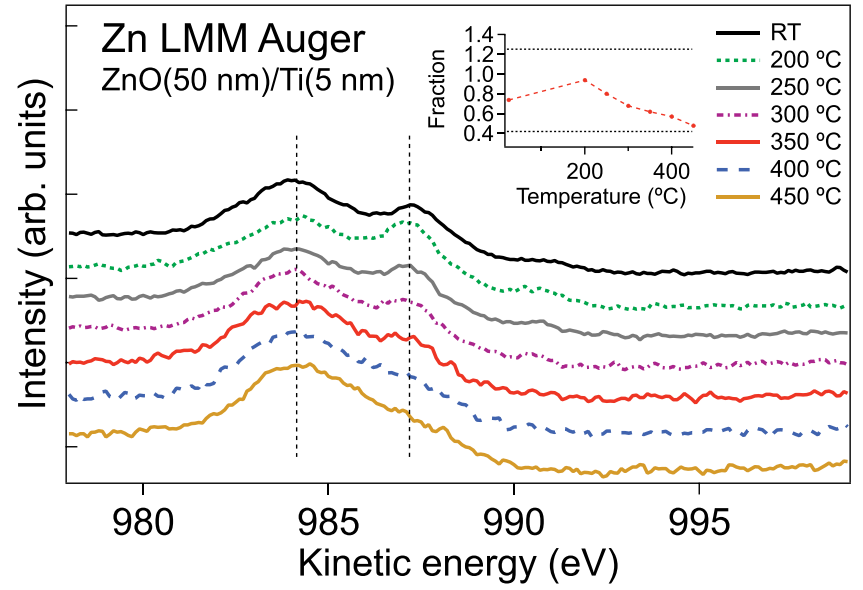

FIG. 8. Zn LMM Auger spectra of $\mathrm{ZnO}(50 \mathrm{~nm}) / \mathrm{Ti}(5 \mathrm{~nm})$ with no capping layer. The peak around $987 \mathrm{eV}$ kinetic energy is characteristic to metallic $\mathrm{Zn}$. The deposition of $\mathrm{Ti}$ on $\mathrm{ZnO}$ clearly leads to a reduction of $\mathrm{ZnO}$. The inset shows the intensity ratio $\mathrm{Zn} / \mathrm{ZnO}$ at the kinetic energies represented by the dotted lines in the main figure. The top and bottom dotted lines in the insert correspond to values obtained from reference metallic $\mathrm{Zn}$ and $\mathrm{ZnO}$ samples, respectively.

top and bottom black dashed lines in the inset indicate the ratio for the metallic $\mathrm{Zn}$ and $\mathrm{ZnO}$ samples, respectively. The $\mathrm{ZnO}$ is reduced by the top Ti layer in the as deposited sample and becomes even more reduced as the oxygen is diffusing from the $\mathrm{ZnO}$ into the $\mathrm{Ti}$ after annealing at $200^{\circ} \mathrm{C}$. For temperatures above $200{ }^{\circ} \mathrm{C}$, the oxygen from the $\mathrm{ZnO}$ bulk diffuses towards the surface and oxidizes the reduced $\mathrm{Zn}$ at the interface. This corresponds well with the observed line shapes of $\mathrm{Zn} 2 \mathrm{p}_{3 / 2}$ in Fig. 6(b) which showed a strong $\mathrm{Zn}^{0}$ component after annealing at $200^{\circ} \mathrm{C}$.

\section{SUMMARY AND CONCLUSION}

We can summarize our results as follows: Fig. 9 (left) shows the actual sample geometry before annealing in contrast to the designed stack shown in Fig. 1. The as-deposited layers contained a certain amount of $\mathrm{Ti}$ oxide. In the case of $\mathrm{ZnO}$ deposited onto a Ti layer, the oxidation occurred during exposure of $\mathrm{Ti}$ to the reactive oxygen plasma (Fig. 4(b)).
When Ti was deposited onto $\mathrm{ZnO}$, we observed a metallic component of $\mathrm{Zn}$, reflecting the formation of $\mathrm{O}$ vacancies (Figs. 4(a) and 8) confirming the suggestion of earlier publications. ${ }^{4}$ The extent of the $\mathrm{ZnO}$ reduction was limited to the near proximity of the as-deposited interface. This chemical reaction extended further during annealing at $200^{\circ} \mathrm{C}$, as a stronger metallic component of the $\mathrm{Zn}$ peak was observed. This could explain the decrease of interface resistance reported by some authors. ${ }^{4-6}$ At the same time, a thicker $\mathrm{TiO}_{x}$ layer was formed suggesting the reduction of $\mathrm{ZnO}$ by $\mathrm{Ti}$ at the interface. Annealing at $350{ }^{\circ} \mathrm{C}$ resulted in re-oxidation of the reduced $\mathrm{ZnO}$ at the interface and a deeper oxidation of the Ti layer. It suggests that the bulk diffusion of oxygen was activated at this temperature. It is well known that sputter-deposited films contain a large amount of structural and chemical defects. These defects can cause large residual stresses. A previous study of the residual stress in similar $\mathrm{ZnO}$ layers showed that a vast stress relaxation occurred at around $300^{\circ} \mathrm{C}$ (Ref. 22) which was attributed to structural reorganization of the film and defect repair. Other authors evoked the apparent increase of oxygen diffusion as being induced by the onset of diffusion of $\mathrm{H}$ and $\mathrm{OH}$ groups present in sputtered $\mathrm{ZnO} .{ }^{23,24}$ At $550{ }^{\circ} \mathrm{C}$ oxygen, $\mathrm{Zn}$ and $\mathrm{Ti}$ atoms all become mobile and interdiffusion drives the formation of a new compound. Presumably, in the $\mathrm{ZnO} / \mathrm{Ti} / \mathrm{ZnO}$ stack, a similar scenario occurs at the lower interface. However, the Ti oxidation is much more pronounced in the as-deposited film due to the top $\mathrm{ZnO}$. Fig. 9 (right) is a schematic presentation of the films after annealing. Apparently, the two interfaces, $\mathrm{Ti} / \mathrm{ZnO}$ and $\mathrm{ZnO} / \mathrm{Ti}$, behave differently during annealing. In addition to the differences in their structure and initial conditions discussed above, the rate of inter-diffusion and oxygen exchange can be influenced by asymmetric intermixing as observed for other systems. ${ }^{25-28}$

In conclusion, HAXPES was successfully used to probe $\mathrm{ZnO} / \mathrm{Ti}$ interfaces in multilayers. It provided a detailed view of the composition and the oxidation state of $\mathrm{Ti}$ and $\mathrm{Zn}$ atoms close to the interface in as-deposited films and after annealing. The results unveil a strong deviation between the stacks as-designed, as-deposited and after annealing due to the reactivity of the Ti layer, Figs. 1 and 9. The order of

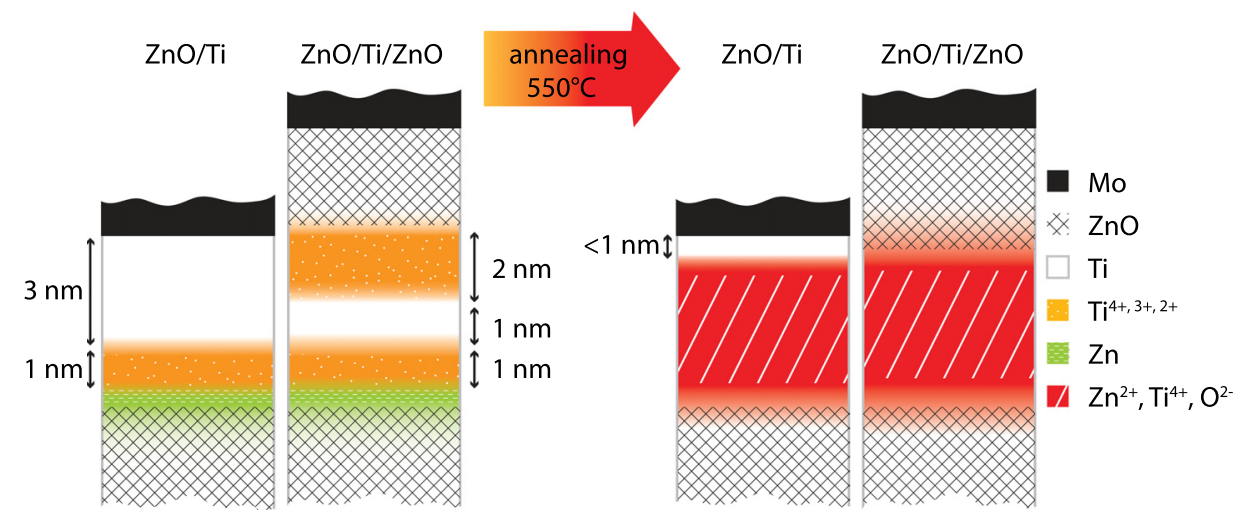

FIG. 9. Actual sample geometry of $\mathrm{ZnO} / \mathrm{Ti}$ and $\mathrm{ZnO} / \mathrm{TiZnO}$ samples, both in as-deposited (left) and after annealing to $550{ }^{\circ} \mathrm{C}$ (right). In the as-deposited samples, an oxidation of $\mathrm{Ti}$ is found at both the $\mathrm{ZnO} / \mathrm{Ti}$ and $\mathrm{Ti} / \mathrm{ZnO}$ interfaces. When the Ti is deposited on $\mathrm{ZnO}$, a metallic character of $\mathrm{Zn}$ is formed due to reduction of $\mathrm{ZnO}$ at the interface. The figure illustrates the location of $\mathrm{Zn}$ rather than the formation of a continuous layer. After annealing to $550{ }^{\circ} \mathrm{C}$, a weak $\mathrm{Ti}$ metallic component still exist in the $\mathrm{ZnO} / \mathrm{Ti}$ sample but the majority of the Ti has intermixed with the $\mathrm{ZnO}$. 
deposition proved to be an important parameter impacting both the room temperature structure and the reaction kinetics upon annealing. These results clearly demonstrate the power of HAXPES to probe the link between processing conditions and the internal structure of complex multilayered stacks.

\section{ACKNOWLEDGMENTS}

We acknowledge the Helmholtz-Zentrum Berlin for provision of synchrotron radiation beamtime at beamline $\mathrm{KMC}-1$ of BESSY II. The research leading to these results has received funding from the European Community's Seventh Framework Programme (FP7/2007-2013) under Grant Agreement No. 312284. The authors also gratefully acknowledge funding from the Swedish Energy Agency, the Swedish Resarch Council (VR) and StandUp for Energy.

${ }^{1}$ K. Ip, K. H. Baik, Y. W. Heo, D. P. Norton, S. J. Pearton, J. R. LaRoche, B. Luo, F. Ren, and J. M. Zavada, "Annealing temperature dependence of contact resistance and stability for ti/al/pt/au ohmic contacts to bulk n-zno,” J. Vac. Sci. Technol. B 21(6), 2378-2381 (2003).

${ }^{2}$ U. Ozgur, Y. I. Alivov, C. Liu, A. Teke, M. A. Reshchikov, S. Dogan, V. Avrutin, S.-J. Cho, and H. Morkoc, "A comprehensive review of zno materials and devices," J. Appl. Phys. 98(4), 041301 (2005).

${ }^{3}$ S. Grachev, A. Mehlich, J.-D. Kamminga, E. Barthel, and E. Søndergård, "High-throughput optimization of adhesion in multilayers by superlayer gradients," Thin Solid Films 518(21), 6052-6054 (2010).

${ }^{4}$ H. S. Yang, D. P. Norton, S. J. Pearton, and F. Ren, "Ti/au n-type ohmic contacts to bulk zno substrates," Appl. Phys. Lett. 87(21), 212106 (2005).

${ }^{5}$ J. Chen, T. Anderson, S. Jang, F. Ren, Y. Li, H.-S. Kim, B. Gila, D. Norton, and S. Pearton, "Ti/au ohmic contacts to al-doped n-zno grown by pulsed laser deposition," J. Electrochem. Soc. 153(5), G462-G464 (2006). ${ }^{6}$ H.-K. Kim, S.-H. Han, T.-Y. Seong, and W.-K. Choi, "Electrical and structural properties of ti/au ohniic contacts to n-zno," J. Electrochem. Soc. 148(3), G114-G117 (2001).

${ }^{7}$ M. Gorgoi, S. Svensson, F. Schäfers, G. Öhrwall, M. Mertin, P. Bressler, O. Karis, H. Siegbahn, A. Sandell, H. Rensmo, W. Doherty, C. Jung, W. Braun, and W. Eberhardt, "The high kinetic energy photoelectron spectroscopy facility at bessy progress and first results," Nucl. Instrum. Methods Phys. Res. A 601(1-2), 48-53 (2009).

${ }^{8}$ S. Granroth, R. Knut, M. Marcellini, G. Andersson, S. Svensson, O. Karis, M. Gorgoi, F. Schäfers, W. Braun, W. Eberhardt, W. Olovsson, E. Holmström, and N. Mårtensson, "Investigation of interface properties of ni/cu multilayers by high kinetic energy photoelectron spectroscopy," Phys. Rev. B 80(9), 094104 (2009).

${ }^{9}$ R. Knut, P. Svedlindh, O. Mryasov, K. Gunnarsson, P. Warnicke, D. Arena, M. Björck, A. Dennison, A. Sahoo, S. Mukherjee, D. Sarma, S. Granroth, M. Gorgoi, and O. Karis, "Interface characterization of co2mnge/rh2cusn heusler multilayers,” Phys. Rev. B 88(13), 134407 (2013).
${ }^{10}$ M. Sing, G. Berner, K. Goß, A. Müller, A. Ruff, A. Wetscherek, S. Thiel, J. Mannhart, S. Pauli, C. Schneider, P. Willmott, M. Gorgoi, F. Schäfers, and R. Claessen, "Profiling the interface electron gas of laalo3/srtio3 heterostructures with hard x-ray photoelectron spectroscopy," Phys. Rev. Lett. 102(17), 176805 (2009).

${ }^{11} \mathrm{~B}$. Johansson and N. Mårtensson, "Core-level binding-energy shifts for the metallic elements," Phys. Rev. B 21, 4427-4457 (1980).

${ }^{12}$ M. Biesinger, L. Lau, A. Gerson, and R. Smart, "Resolving surface chemical states in XPS analysis of first row transition metals, oxides and hydroxides: Sc, Ti, V, Cu and Zn," Appl. Surf. Sci. 257(3), 887-898 (2010).

${ }^{13}$ D. Coster and R. D. L. Kronig, "New type of auger effect and its influence on the x-ray spectrum," Physica 2(1-12), 13-24 (1935).

${ }^{14}$ J. Végh, "The shirley background revised," J. Electron Spectrosc. Relat. Phenom. 151, 159-164 (2006), and references therein.

${ }^{15}$ S. Doniach and M. Sunjic, "Many-electron singularity in X-ray photoemission and X-ray line spectra from metals," J. Phys. C 3(2), 285 (1970).

${ }^{16}$ C.-T. Wang and J.-C. Lin, "Surface nature of nanoparticle zinc-titanium oxide aerogel catalysts," Appl. Surf. Sci. 254, 4500-4507 (2008).

${ }^{17}$ D. Iusan, R. Knut, B. Sanyal, O. Karis, O. Eriksson, V. Coleman, G. Westin, J. Wikberg, and P. Svedlindh, "Electronic structure and chemical and magnetic interactions in zno doped with co and al: Experiments and ab initio density-functional calculations," Phys. Rev. B 78(8), 085319 (2008).

${ }^{18}$ R. Knut, J. Wikberg, K. Lashgari, V. Coleman, G. Westin, P. Svedlindh, and O. Karis, "Magnetic and electronic characterization of highly codoped zno: An annealing study at the solubility limit," Phys. Rev. B 82(9), 094438 (2010).

${ }^{19}$ L. J. Brillson and Y. Lu, "Zno schottky barriers and ohmic contacts," J. Appl. Phys. 109(12), 121301 (2011).

${ }^{20}$ S. Tougaard: QUASES-IMFP-TPP2M. Software packages to characterize surface nano-structures by analysis of electron spectra, see http:// www.quases.com/products/quases-imfp-tpp $2 \mathrm{~m} /$.

${ }^{21} \mathrm{U}$. Steinike and B. Wallis, "Formation and structure of ti-zn-oxides," Cryst. Res. Technol. 32(1), 187-193 (1997).

${ }^{22}$ P. Renault, C. Krauss, E. L. Bourhis, G. Geandier, A. Benedetto, S. Grachev, and E. Barthel, "In situ thermal residual stress evolution in ultrathin zno and ag films studied by synchrotron x-ray diffraction," Thin Solid Films 520(5), 1390-1394 (2011).

${ }^{23}$ E. V. Monakhov, A. Y. Kuznetsov, and B. G. Svensson, "Zinc oxide: bulk growth, role of hydrogen and schottky diodes," J. Phys. D: Appl. Phys. 42(15), 153001 (2009).

${ }^{24}$ G. A. Shi, M. Saboktakin, M. Stavola, and S. J. Pearton, “"Hidden hydrogen' in as-grown zno," Appl. Phys. Lett. 85(23), 5601-5603 (2004).

${ }^{25}$ P. Süle, M. Menyhárd, L. Kótis, J. Lábár, and W. F. Egelhoff, "Asymmetric transient enhanced intermixing in pt/ti," J. Appl. Phys. 101(4), 043502 (2007).

${ }^{26} \mathrm{G}$. Sharma, R. Gupta, and A. Gupta, "Study of interfacial modification in fe/ag multilayer with thermal annealing using x ray standing wave," AIP Conf. Proc. 1349(1), 661-662 (2011).

${ }^{27}$ Q. Zhong, Z. Zhang, S. Ma, R. Qi, J. Li, Z. Wang, P. Jonnard, K. L. Guen, and J.-M. André, "Thermally induced structural modification in the al/zr multilayers," Appl. Surf. Sci. 279, 334-342 (2013).

${ }^{28}$ A. Gupta, D. Kumar, and V. Phatak, "Asymmetric diffusion at the interfaces in fe/si multilayers,” Phys. Rev. B 81, 155402 (2010). 